\title{
Using seasonal stochastic dynamic programming to identify optimal management decisions that achieve maximum economic sustainable yields from grasslands under climate risk
}

by Behrendt, K., Cacho, O., Scott, J.M. and Jones, R.

Copyright, Publisher and Additional Information: This is the author accepted manuscript. The final published version (version of record) is available online via Csiro Publishing Please refer to any applicable terms of use of the publisher.

This version is made available under the CC-BY-ND-NC licence:

https://creativecommons.org/licenses/by-nc-nd/4.0/legalcode

DOI: https://doi.org/10.1016/j.agsy.2016.03.001

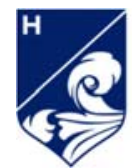

Harper Adams University 
Using Seasonal Stochastic Dynamic Programming to identify optimal management decisions that

2 achieve maximum economic sustainable yields from grasslands under climate risk

3 Karl Behrendt ${ }^{\mathrm{A}, \mathrm{D}}$, Oscar Cacho ${ }^{\mathrm{B}}$, James M. Scott ${ }^{\mathrm{B}}$, and Randall Jones ${ }^{\mathrm{C}}$

$4{ }^{\mathrm{A}}$ Graham Centre for Agricultural Innovation (NSW Department of Primary Industries and Charles Sturt

5 University), Charles Sturt University, School of Agricultural and Wine Science, Orange, NSW 2800,

6 Australia

$7 \quad$ B University of New England, Armidale NSW 2351, Australia.

$8 \quad{ }^{\mathrm{C}} \mathrm{NSW}$ Department of Primary Industries, Forest Road, Orange NSW 2800, Australia.

$9 \quad$ DAuthor for correspondence: email: kbehrendt@csu.edu.au; Phone: +61 263657119

\section{Abstract}

11 There are significant challenges in managing the trade-offs between the production of pastures and

12 grazing livestock for profit in the short term, and the persistence of the pasture resource in the longer

13 term under stochastic climatic conditions. The profitability of using technologies such as grazing

14 management, fertiliser inputs and the renovation of pastures are all influenced by complex inter-

temporal relations that need to be considered to provide suitable information for managers to enhance

tactical and strategic decision making.

In this study pasture is viewed as an exploitable renewable resource with its state defined by total

pasture quantity and the proportion of desirable species in the sward. The decision problem was

formulated as a stochastic dynamic programming (SDP) model where the decision variables are

seasonal stocking rate and pasture re-sowing and the objective is to maximise the present value of

future economic returns. The solution defines the optimal seasonal decisions for all intervening states

of the system as uncertainty unfolds.

The model was applied to a representative farm in the high rainfall temperate pasture zone of Australia and the pasture states under which tactical grazing rest, low stocking rates and pasture re-sowing are optimal were identified. Results provide useful general insights as well as specific prescriptions for the case study farm. The framework developed in this paper provides a means of identifying optimal tactical and strategic decisions that achieve maximum sustainable economic yields from grazing systems.

\section{Keywords}




\section{Introduction}

Managing any grazing system effectively requires an understanding of the complex dynamic interactions between the state of the pasture resource and the application of different technologies while also considering the influences of a stochastic climate on decision making. Relevant technologies include grazing management, fertiliser application and the renovation of pastures through the introduction of new species. The decision maker needs to account for multiple and conflicting objectives of pasture resource production, persistence of desirable pasture species, livestock productivity and profit (Behrendt et al., 2013a).

The decisions for developing and managing a pasture resource occur at different stages over the planning horizon. For example, in most grazing enterprises, the renovation of a pasture with sown species is a long-term strategic decision, whereas the application of fertiliser tends to operate at a more tactical level within production years. Grazing management includes both stocking rate and time livestock spend grazing a paddock (and the corresponding rest periods from grazing) as decision variables. This means that grazing management operates at a tactical level, over periods ranging from a year in so-called 'set stocking' systems to days in intensive rotational grazing systems, but it also operates at a strategic level regarding herd management to maintain the required-targeted stocking rate-in self-replacing systems.

The benefits of each technology cannot be considered in isolation because of the presence of interactions between the technologies and sources of exogenous risk to the grazing system, such as climate and price variability (Antle, 1983; Hutchinson, 1992). These interactions occur over the short term through the production of pasture, and over the longer term through changes in the botanical composition of the pasture, which include both desirable and undesirable species groups (Dowling et al., 2005; Hutchinson, 1992). Botanical composition change has frequently been considered in rangeland studies (Stafford Smith et al., 1995; Torell et al., 1991), but has largely been neglected in temperate grasslands. Solutions to the complex problem of defining inter-temporal trade-offs between the productivity of a grazing system and the persistence of both desirable and undesirable species within pastures, can be obtained by modelling grasslands as exploitable renewable resources (Clark, 1990) using a bioeconomic approach. In summary, the farm manager faces a complex, dynamic decision problem that involves multiple and conflicting objectives of pasture resource production and persistence, livestock productivity, and profit. 
The decision problem sits within a dynamic and risky environment, with investments in sowing pastures, building (and depleting) soil fertility and grazing management being made whilst considering the state of the pasture resource as it responds to uncertain climatic conditions. In essence, this is a sequential decision problem (Behrendt et al., 2013a), where producers manage the grazing system by making both tactical and strategic decisions at intervening states of the system as uncertainty unfolds (Trebeck and Hardaker, 1972). Climate risk is embedded within the sequential decision problem (Behrendt et al., 2013a; Hardaker et al., 1991), influencing the state of the system after decisions are made and before income is received.

The state of the grassland resource at any time can be represented as a set of three state variables: herbage mass, botanical composition, and soil fertility. The pasture state can be influenced by the strategic decisions available to the producer, such as re-sowing of a pasture with desirable species and choosing the most appropriate stocking rate, as well as tactical decisions, such as fertiliser application and grazing management. In a multi-area grazing system, such as a farm with multiple paddocks, a mosaic of pasture states and soil fertility conditions exist and the decision problem becomes more complex.

The exclusion of seasonal variability and tactical responses embedded in a sequential decision process has been shown to provide incorrect estimates of the economic benefits of a technology involved in complex biological and dynamic systems (Marshall et al., 1997). Finding optimal development paths in the pasture resource problem requires embedded risk to be considered. That is, any development plan needs to be adjusted over time depending on uncertain events and states that influence economic returns and occur as the farm plan evolves-. This process-situation defines conditions whereby the pasture resource problem may be formulated as a stochastic dynamic programming problem (Kennedy, 1986).

In this paper, we develop a bioeconomic framework to optimise pasture development and management where both pasture quantity and quality are considered within a stochastic environment. The model is used to derive optimal tactical and strategic decision rules that will result in maximum economic sustainable yields from the pasture resource.

\section{Methods}

The framework developed takes into account the impact of embedded climate risk, technology application and management on the botanical composition of the pasture resource over time which, in 


\begin{tabular}{|l|l}
91 \\
92 \\
93 \\
94 \\
95 \\
96 \\
97 \\
98 \\
99 \\
100 \\
101 \\
102 \\
103 \\
109 \\
105 \\
106 \\
107 \\
108 \\
109
\end{tabular}

turn, impacts on optimal management strategies. This is achieved through the use of two simulation

models, AusFarm (CSIRO, 2007) and the dynamic pasture resource development (DPRD) simulation

model, described in Behrendt (2008), Behrendt et al. (2013a) and Behrendt et al. (2013b). The

AusFarm model, a complex biophysical simulation model, was calibrated to data from the Cicerone

Project farmlet experiment (Scott et al., 2013), and it was used to derive pasture production parameters

for the DPRD model. The DPRD model was then used to solve the decision problem using a seasonal

stochastic dynamic programming (SDP) frameworkThis is achieved through the development of a

dynamic pasture resource development (DPRD) simulation model, described in Behrendt (2008),

Behrendt et al. (2013a) and Behrendt et al. (2013b), and which is integrated into a seasonal stochastic

dynamic programming (SDP) framework.

\subsection{Seasonal stochastic dynamic programming model}

The SDP solution process uses four seasonal transition probability matrices that are applied sequentially to solve a recursive equation with the objective of maximising the expected net present value of returns from sheep production systems over the long run. The SDP model finds seasonally optimal tactical and strategic decision rules in terms of stocking rates and pasture sowing, as functions of pasture mass and composition (proportion of desirables).

Two SDP recursive equations represent the four seasons._This is required due to all four seasons being embedded within a year type, rather than each season remaining stochastically independent.

The SDP recursive equation for the first three seasons starting with autumn is:

$$
V_{t}^{s}\left(\mathbf{z}_{t}^{s}\right)=\max _{\mathbf{u}_{t}^{s}}\left[E\left[\pi\left(\mathbf{z}_{t}^{s}, \mathbf{u}_{t}^{s}\right)\right]+\delta_{s} E\left[V_{t}^{s+1}\left(\theta^{s}\left(\mathbf{z}_{t}^{s}, \mathbf{u}_{t}^{s}\right)\right)\right] ; \text { for } s=1,2,3\right.
$$

111

112

The SDP recursive equation for the final season, summer, in a year is:

$$
V_{t}^{s}\left(\mathbf{z}_{t}^{s}\right)=\max _{\mathbf{u}_{t}^{s}}\left[E\left[\pi\left(\mathbf{z}_{t}^{s}, \mathbf{u}_{t}^{s}\right)\right]+\delta_{s} E\left[V_{t+1}^{1}\left(\theta^{s}\left(\mathbf{z}_{t}^{s}, \mathbf{u}_{t}^{s}\right)\right)\right]\right] ; \text { for } s=4
$$

where $s$ denotes the season $(s=1, \ldots, 4) ; t$ denotes the year; $V_{t}^{s}$ is the optimal value function for the given season and year; $E$ is the expectation operator; $\pi$ is the stage return function for a given season; $\mathbf{z}_{t}^{s}$ is a state vector consisting of three state variables (defined below) for the given season and year; $\mathbf{u}_{t}^{s}$ is a decision vector consisting of two decision variables (defined below) for the given season and year; $\theta^{s}$ is the transformation function for the given season; and $\delta_{s}$ is the discount factor $\left(\delta_{s}=1 /(1\right.$ 
$\left.+\rho_{s}\right)$ ). The seasonal discount rate, $\rho_{s}$, is pro-rated from the annual discount rate, $\rho$, based on the length of the season in days $\left(\rho_{s}=\rho \cdot D_{s} / 365\right)$. The difference between equations 1 and 2 is in the season and year indexes of the future value of the system, $V_{t}^{s+1}$, which refers to the next season in the current year, and $V_{t+1}^{1}$ refers to the first season in the next year.

The state vector $\mathbf{z}_{t}^{s}$ contains three state variables:

$$
\mathbf{z}_{t}^{s}=\left(x_{t}^{s}, y d_{t}^{s}, y u d_{t}^{s}\right)
$$

where $x$ is the proportion of desirable species in the sward and represents their basal area within the paddock; $y d$ is the herbage mass of desirable species in the sward (kg Dry Matter/ha) and yud is the herbage mass of undesirable species $(\mathrm{kg} \mathrm{DM} / \mathrm{ha})$. All state variables are measured at the start of season $s$ in year $t$.

The decision vector $\mathbf{u}_{t}^{s}$ contains two decision variables:

$$
\mathbf{u}_{t}^{s}=\left(s r_{t}^{s}, r s_{t}^{s}\right)
$$

where $s r$ is the stocking rate (hd/ha) and $r s$ is the decision to re-sow the pasture, with both decisions taken at the start of season $s$ in year $t$.

The transformation functions, $\theta^{s}$, are represented by transition probability matrices derived through Monte Carlo simulation with the biological model described in Behrendt et al. (2013a) and Behrendt et al. (2013b) as described below, and using stochastic multipliers derived from climatic data as explained in Behrendt (2008). The biological model defines the expected levels of production and the impact of disturbance as determined by stocking rate and re-sowing decisions.

To solve the problem we define the Markovian transition probability matrices $\mathbf{P}^{\mathrm{s}}$ and rewrite the expectation operators in discrete terms. The elements $P_{i j}^{s}$ of matrix $\mathbf{P}^{\mathrm{s}}$ represent the probability of moving from state $i$ in season $s$ to state $j$ in season $s+1$. The elements of the transition matrices given the decision $\mathbf{u}^{\mathrm{s}}$ are:

$$
P_{i j}^{s}\left(\mathbf{u}^{s}\right)=P\left(\mathbf{z}_{j}^{s+1} \mid \mathbf{z}_{i}^{s}, \mathbf{u}^{s}, r^{s}\right) P_{i j}^{s}\left(\mathbf{u}^{s}\right)=P\left(\mathbf{z}_{j}^{s+1} \mid \mathbf{z}_{i}^{s}, \mathbf{u}^{w}, r^{s}\right)
$$




$$
E\left[\pi\left(\mathbf{z}_{i}^{s}, \mathbf{u}^{s}\right)\right]=\sum_{j} P\left(r_{j}\right) \pi\left(\mathbf{z}_{i}^{s}, \mathbf{u}^{s}, r_{j}\right)
$$

$$
E\left[V\left(\theta^{s}\left(\mathbf{z}_{i}^{s}, \mathbf{u}^{s}\right)\right)\right]=\sum_{j} P_{i j}^{s}\left(\mathbf{u}^{s}\right) V\left(\mathbf{z}_{j}^{s+1}\right)
$$

subject to:

$$
\sum_{j} P\left(r_{j}\right)=1
$$

$\sum_{j} P_{i j}^{s}\left(\mathbf{u}^{s}\right)=1 ;$ for all $i$

Since there are only four seasons, the season counter $s+1$ is set back to 1 when $s=4$ in the equations above. The rainfall index $\left(r^{s}\right)$ is not explicitly represented as a functional form, but it is introduced through stochastic multipliers (Cacho et al., 1999) for pasture growth parameters as explained in Behrendt (2008)

The SDP model is solved by value iteration (Kennedy, 1986) until policy convergence is obtained, with the resulting $\mathbf{u}^{s *}\left(\mathbf{z}^{s}\right)$ representing the optimal decision rule contingent on the state of the sward for each season. This is an autonomous problem and hence the solution applies to an infinite planning horizon.

To solve this problem requires the state and decision variables that make up the vectors $\mathbf{z}_{t}^{s}$ and $\mathbf{u}_{t}^{s}$ to be expressed as finite sets. Table 1 presents the state variables and their boundaries used to generate the Transition Probability Matrices (TPM). The number of states, $n_{z}$, defines the size of the TPM $\left(\mathbf{P}^{\mathrm{s}}\left(\mathbf{u}^{\mathrm{s}}\right)\right)$

for a season and decision, and represents the total number of possible combinations of the initial states that define $\mathbf{z}_{t}^{s}$ (equation 3). In this case, 10 states of $y d$ by 10 states of $y u d$ by 10 states of $x$ make a total of 1000 possible combinations and initial states (Table 2). Therefore $n_{z}=1000$ and each TPM has dimensions of $1000 \times 1000$.

\section{Insert Table 1Table 1 near here \\ Insert Table 2Table 2 near here}

Of the two decision variables that make up the decision vector $\mathbf{u}_{t}^{s}$, one is tactical, defining grazing management and the other is strategic, defining capital investment in the pasture resource. The stocking rate decision, $s r$, is made at the start of each season and provides the opportunity for the implementation of a range of grazing pressures or tactical grazing rests to benefit production, economic 
returns and future botanical composition. The values of $s r$ used are $0,2,4,8,10,15,20,30,40$, and 50 dry sheep equivalent (DSE) per ha, where a DSE is a standard unit of livestock feed requirements (Davies, 2005) and equivalent to a standard reference weight of $50 \mathrm{~kg}$ in the DPRD model (Behrendt, 2008; Freer et al., 2007). The decision to renovate a pasture with sown species, $r s$, provides an opportunity for future production to be adjusted through a strategic capital investment. The decision to replace a pasture $(r s=1)$ is always accompanied by a stocking rate of $0 \mathrm{hd} / \mathrm{ha}$.

In total there are 11 sets of decisions that make up the decision vector $\mathbf{u}$ (Table 3 ). The decision vector is applied to each season and initial state. This makes a total combination of 44,000 initial states, seasons and decision variables simulated to populate the TPMs required to solve the SDP model.

\section{Insert Table 3 Table 3 near here}

Soil fertility is an important variable that influences the decision to apply fertiliser, but its inclusion as an additional state variable would have made the dimensionality of the problem too large to be solved within a practical length of time, given the need to ensure the TPM was sensitive enough to reflect changes between pasture states. As a compromise the impact of different soil fertility regimes was investigated based on earlier studies into optimal fertiliser decisions (Behrendt et al., 2013b; Godden and Helyar, 1980; Woodward, 1996). Three sets of TPMs were generated to represent three different soil fertility regimes:

a. High input system: high initial level of soil phosphorus (35 ppm Colwell P (Colwell, 1963)) and high application rates of single superphosphate fertiliser $(150 \mathrm{~kg} / \mathrm{ha} / \mathrm{year})$ to maintain the required level of soil phosphorus.

b. Moderate input system: moderate initial level of soil phosphorus (20 ppm Colwell P) and moderate application rates of single superphosphate fertiliser $(100 \mathrm{~kg} / \mathrm{ha} / \mathrm{year})$.

c. Low input system: low initial level of soil phosphorus (10 ppm Colwell P) and low application rates of single superphosphate fertiliser $(42 \mathrm{~kg} / \mathrm{ha} / \mathrm{year})$.

\subsection{Dynamic pasture resource development model}

The components of the DPRD simulation model are derived from a range of previous studies into pasture and population dynamics, including competition within the sward structure and growth, sheep production and economics. The calibration and validation of the model has been presented through its 
application to a case study region in the high rainfall temperate perennial pasture zone of south eastern Australia (Behrendt et al., 2013a).

The method applied in the DPRD model operates at the paddock level and incorporates two stages of modelling the change in pasture biomass: within a season and between seasons. In a single production year, four representative seasons have been defined that relate to tactical and strategic decision points within a grazing system, the biophysical characteristics of plant and functional group phenology and growth, and known periods associated with botanical composition change within pastures. In each season, modelling of pasture growth and consumption by grazing livestock operates on a daily time step (Figure 1). The empirical pasture composition sub model within the DPRD model adapts the method proposed by Loewer (1998) on the use of 'partial' paddocks, with the space occupied by species assumed to be temporally variable and respond to climate, and-management and inputs. Between seasons the relative areas occupied by desirable and undesirable species groups within the whole sward are modelled using exploited population growth modelling (Clark, 1990). This method uses differential equations to describe the change in the population of desirable species measured as the change in their basal area within the paddock. The model combines a logistic growth function in the absence of grazing with the impact of grazing on the desirable component of the sward (Behrendt et al., 2013b). This method uses differential equations describing desirable species population growth, measured as the change in the area of the paddock they oceupy (using a logistic growth function) and the impact of harvesting by livestock (Behrendt et al., 2013b). This approach encapsulates-adapts the concepts of state and transition models of rangelands (Westoby et al., 1989), with the benefit of an indefinite number of pasture states and responses to climate, grazing and input factors. The approach is analogous to in-field measures of basal areas of pasture species and is similar to the methods of basal area adjustments applied in some rangeland models (Stafford Smith et al., 1995). Separation of pasture yield and basal area of different species groups is justified as basal area provides a more meaningful and stable indicator of ecological or botanical composition change than pasture yield (Cook et al., 1978b), and allows the desirable components within the sward to increase their basal area over time, even when no re-sowing occurs. This assumption is supported by field evidence, where degraded sown pastures increase their basal areas under conditions of high soil fertility and in response to grazing rests, with a consequent increase in the proportion of the sward that is occupied by desirable native or introduced species (Cook et al., 1978a; Garden et al., 2000). Within the DPRD model, parameters for 
net pasture production, quality and botanical composition are varied between seasons but remain constant within a season, with four sequential seasons in a year type.

\section{Insert Figure 1Figure 1 near here}

The integration of the DPRD model into the SDP model occurs at seasonal decision stages. As grazing management can operate over periods ranging from days under intensive rotational grazing systems to a whole year under set stocked systems, it is desirable to simulate short decision intervals (Cacho et al., 1995). However, allowing too short a decision interval increases complexity and computationally constrains the ability to solve the SDP model. The compromise of four seasonal stages is still able to replicate the tactical decisions of stocking rate or complete grazing rests, and maintains the broad assumption that the seasonal adjustment of stocking rate represents tactical adjustments to grazing management.

The optimisation of the pasture resource problem at the paddock level and with four seasonal stages under flexible stocking rate conditions requires flock structure to be flexible. A representative Merino wether enterprise was modelled as the base case to represent the impact of different technologies and management on the production of a particular sheep enterprise. The purpose was to replicate the harvesting of pasture for the production of wool and sheep meat. To adequately represent the production of wool and meat, the livestock sub-model responds to changes in the available herbage mass and changes in botanical composition with its inherent effect on feed quality. The economic submodel assumes no changes in the capital value of livestock between the start and end of the season, with the economic return being the net gross margin return calculated using net weight gain or loss, and the quantity and quality of wool produced within that season. This process allows for sufficient flexibility with respect to stocking rate and pasture utilisation, as it is unconstrained by flock structure.

This is analogous to the common approach of tactically managing a single land area within a larger mosaic of paddocks or land management areas that provide the total feed base for the entire flock. The area modelled in this paper would be used optimally to supply feed through a seasonally based rotational grazing system embedded within a whole farm system.

The DPRD model was parameterised using experimental simulation output from a complex mechanistic grazing systems model, AusFarm (CSIRO, 2007). Complex biophysical models, such as AusFarm, that attempt to model biological systems as closely as possible, are not well suited to run as part of an economic optimisation model, because of the time required to solve each simulation run 
(Cacho, 1998). Hence there was a need to achieve a balance between complexity in the biophysical model and adequacy of information for improved decision making. Achieving this compromise was the driving factor behind the design of the DPRD model and its parameterisation with AusFarm. Supplementary feeding decision rules were also not incorporated for similar reasons to those previously explained for fertiliser. However, supplementary feeding was also excluded as an endogenous decision to ensure dynamic optimisation of the pasture resource was not skewed by implicit supplementary feeding policies. This is because the quantity of supplements offered to grazing animals in the DPRD model influences the economics of fertiliser application, the grazing system, animal performance, pasture production and botanical composition.

To generate the Transition Probability Matrices, the minimal supplementary feeding rules described by Behrendt et al. (2013a) were applied. That is, supplements were offered to grazing animals when necessary, to ensure they do not fall below a condition score of 2.0, or when total sward herbage mass is less than $100 \mathrm{~kg} \mathrm{DM} / \mathrm{ha}$.

\subsection{Case study application}

In order to understand changes in botanical composition of pastures, long term grazing trials are required due to the dynamic and often slow changes in this variable (Dowling et al., 2005; Jones et al., 1995). However, data from short term grazing trials may be used to derive empirical models to answer 'what if' questions, as long as the models adjust composition in response to sporadic events, such as the effect of droughts on soil moisture (Jones et al., 1995). In this study the AusFarm program was calibrated to field experimental data accessed from the Cicerone Project's farming systems experiment (Scott et al., 2013). This experiment was set up as whole farmlet management systems to study the long term profitability of three different input and grazing systems in New South Wales, Australia, over the period from July 2000 to December 2006. Further details of the calibration process have been described by Behrendt et al. (2013a) with the initial state of soil and pasture resources reported at the start of the Cicerone Project experiment (Guppy et al., 2013; Shakhane et al., 2013a) forming the basis for the application of the bioeconomic simulation framework.

Results from the Cicerone farmlet experiment indicated that botanical composition in all of the farmlets changed in response to the level of system inputs and the imposed management (Shakhane et al., 2013b). Over the period of the experiment, there was a general decline in the proportion of sown perennial grasses in the sward with a corresponding increase in the proportion of warm season grasses. 
The data available from the Cicerone Project farmlets, which includes biophysical, managerial and economic data, provided a sound basis for the calibration and demonstration of the AusFarm and DPRD models.

The Cicerone Project operated in climate that is representative of the summer dominant, temperate high rainfall region found in south eastern Australia, $17 \mathrm{~km}$ south of Armidale. The mean annual rainfall over the years of 1968 to 2006 was $745 \mathrm{~mm}$ per annum with approximately $66 \%$ of it falling between October and March (Behrendt et al., 2013c). To parameterise the DRPD model daily climate data for Armidale was used over the 30 year period from 1976 to 2006. This is inclusive of the period over which the Cicerone Project experiment ran (February 2001 to April 2006). A default duplex soil profile with a depth of $700 \mathrm{~mm}$ and 5 layers was used to define the soil type for the Cicerone Project site (A horizon $0-300 \mathrm{~mm}$, B horizon $301-700 \mathrm{~mm}$ ) based on earlier research in the experimental area by McLeod et al. (1998)

The species identified within the paddocks of the Cicerone Project experiment (Shakhane et al., 2013b) were allocated between desirable and undesirable species groups and 6 functional sub-groups (Behrendt, 2008). One minor functional group, being broadleaf plants and weeds, was not modelled as part of the desirable or undesirable species groups. Vulpia spp. and Bothriochloa macra were modelled as the indicative species for the undesirable group, whereas the desirable group was modelled using Austrodanthonia spp., Phalaris aquatica and Trifolium repens. These species were used as they either best represented the dominant species within the functional groups or were the most appropriate species within the limited number of species parameter sets available in AusFarm. To calibrate the Ausfarm model to the experimental data, stocking rates (on a dry sheep equivalent (DSE) basis, which corresponds to a $50 \mathrm{~kg}$ standard reference weight, mature and thermo-neutral merino wether) were calculated from the Cicerone Project experiment database and applied on a daily basis within the AusFarm simulation (Behrendt et al., 2013a). Seasonal sigmoidal pasture growth curves (Cacho, 1993) in the DPRD model were defined based on rate of regrowth as a function of residual dry matter (established using a cut height script) In addition, long term daily quality dry matter distributions within 6 digestibility pools and biomass decay rates were derived from the 30 year Ausfarm simulations for both desirable and non-desirable groups. This was done only for moderate stocking rates of 10 DSE/ha.

\subsection{Numerical Solution}


The linkage between the SDP model and the DPRD model occurs through the estimation of transition probability matrices (TPM) and biophysical matrices for each season. The model was implemented in Matlab (Mathworks_Inc, 2013) and solved by the following steps:

1. Read parameters, set number of states $\left(n_{z}\right)$ and number of decisions $\left(n_{u}\right)$.

2. Run the DPRD model in stochastic mode to derive transition probability matrices and biophysical matrices for each season.

3. Save matrices from step 2 for future use.

4. Set desired prices, costs and discount rate.

5. Read matrices from step 2 into memory.

6. Solve the recursive equation until policy convergence is achieved.

7. Calculate optimal transition matrices.

8. Retrieve optimal solutions for any initial state.

The biophysical matrices created in step 2 have dimensions $\left(n_{z} \times n_{u}\right)$, and they record the expected outcome for each starting state and decision combination for the given season. The biophysical predictions recorded are body weight gain, wool grown, wool mean fibre diameter, and quantity of supplements fed. These matrices are then used to calculate the stage or seasonal returns in step 6 using the DPRD economic sub-model. This approach allows prices to be changed without requiring the transition probability matrices to be re-calculated, as this step is expensive in terms of time (taking approximately 72 hours to solve).

The process for deriving the TPMs for each season in step 2 is as follows:

i. Select a set of $n$ stochastic multipliers to represent a random sequence of years to be used in all simulations to capture the effect of weather on pasture growth.

ii. For each Set the-initial state $z_{i}$ of the pasture (pasture mass, desirables, undesirables) for row $i$

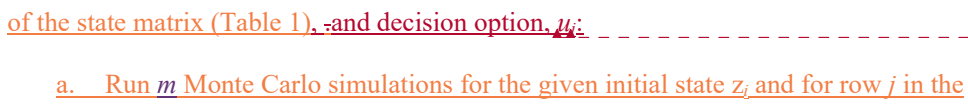

Formatted: Font: Italic
Formatted: Font: Italic, Subscript
Formatted


b.

Inerease the decision counter i and retm to step iii until the process has been completed for all decision options.

Increase the state counter $i$ and return to step ii until the process has been completed for all initialstates:

This is a simplified representation of a complex process that involves seasonal changes in pasture quantity and quality. The design of the model ensures the Markov property is satisfied: the state transition probabilities depend only on the initial state and a random weather variable. This design implicitly assumes that any effects of weather events that occurred before time $t$ on the outcomes at $t+1$ are captured by the values of the state variables at $t$.

This process (steps 1 to 8 ) has been applied in other studies to investigate how changing emphasis on the value of production outputs for different sheep production systems (wool and meat) and input costs (pasture sowing) changes the optimal decision vector (Behrendt et al., 2013a). In this study we conducted sensitivity testing of the effect of the discount rate on optimal decision rules and long-run probabilities under optimal management. The base discount rate used in this analysis was $4.94 \%$ and represented the real discount rate calculated from inflation and nominal interest rate data (plus a margin of $1.5 \%$ ), over the period of 1976 to 2006 (ABARE, 2006). To investigate the sensitivity of the optimal decision to changes in the discount rate, values of $3 \%, 7 \%, 10 \%, 20 \%$ and $50 \%$ were also applied.

The appropriate number of Monte Carlo iterations for the creation of the TPMs and the biophysical matrices were determined from the sum of squared deviations of an arbitrary selection of rows from the $\mathbf{p}^{\mathrm{s}}$ matrices as the number of iterations increased. The process was as follows:

i. A given row $P_{i \bullet}^{s}\left(\mathbf{u}^{s}\right)$ was selected (see equation 5), call this vector $\mathbf{p}_{1 ;}$

ii. The row was populated by running the DPRD for a given number $(m)$ of iterations starting with state $i$;

iii. The results were allocated to the corresponding states of $\mathbf{p}_{1}$ and converted to probabilities;

iv. An additional iteration was run (as in step 2) and the probabilities resulting from $m+1$ iteration

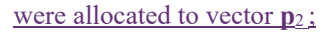

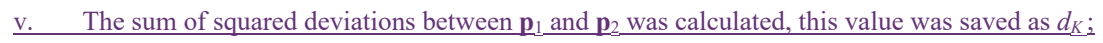

Formatted

Formatted: Lowered by 6 pt 
vi. The values were updated as $\mathbf{p}_{1}=\underline{\mathbf{p}}_{2}, m=m+1$;

vii. Steps iv to vi were repeated until the value of $d_{\underline{K}}$ was sufficiently close to zero.

The convergence in the value of probabilities occurred with about 200 iterations of the Monte Carlo simulation of the DPRD model, and this was the number of iterations $(m)$ used to generate the TPMs.

The optimal transition matrices (step 7) are created based on the optimal solution $\mathbf{u}^{s *}\left(\mathbf{z}^{s}\right)$, by selecting the appropriate rows from the transition probability matrices $\mathbf{P}^{\mathrm{s}}\left(\mathbf{u}^{\mathrm{s} *}\left(\mathbf{z}^{\mathrm{s}}\right)\right)$. The resulting matrices $\mathbf{P}^{\mathrm{s} *}$ have dimensions $\left(n_{z} \times n_{z}\right)$ and represent the state transition probabilities when the optimal decision rule is applied for the given season $s$.

The stationary (long-run) state distributions under optimal management were calculated numerically by setting an arbitrary initial state $w_{0}$ and repeating the operation

$w_{t+1}^{s+1}=w_{t}^{s} \mathbf{P} s *$

until the value of $w_{t}^{s}$ converges for all seasons. This vector $\left(w_{t}{ }^{s^{*}}\right)$ represents the optimal stationary joint distribution for season $s$. These joint distributions are then used to derive univariate distributions of pasture mass and proportion of desirables, which then allow us to define approximate targets for management. The optimal expected path for any initial state (step 8) is calculated by defining an initial state vector $z_{\theta}$ of dimensions ( $\left(1 \times n_{z}\right)$. This vector contains $a 1$ in the position representing the initial state and 0 everywhere else. A time sequence of optimal states (in a probabilistic sense) is obtained by matrix multiplication:

$\ldots$ (12)

Continuing this process will eventually result in convergence in the seasonal values of. These values represent the long term state probabilities when the system is managed according to the optimat decision rule. ItsThe expected values of these distributions can be interpreted as approximate 
benchmarks for the eptimal target level of pasture mass $\left(y d^{*}\right.$ and $\left.y u d^{*}\right)$ and desirable coverage $\left(x^{*}\right)$ for each season.

In presenting the SDP results, the level of pasture mass is reported as the combined area-weighted average pasture mass available in the whole sward, $y_{C}$, and is calculated as follows:

$$
y_{C}=y d \cdot x+y u d \cdot(1-x)
$$

The appropriate number of Monte Carlo iterations for the creation of the TPMs and the biophysical matrices were determined from the sum of squared deviations of an arbitrary selection of rows from the $\mathbf{p}^{s}$ matrices as the number of iterations increased. The process was as follows

1. A given row was selected (see equation 5 ), call this vector $\mathbf{p}+$;

2. The row was populated by running the DPRD for a given number $(m)$ of iterations starting with state $i$

3. The results were allocated to the corresponding states of $\mathbf{p}_{4}$ and converted to probabilities;

4. An additional iteration was run (as in step 2) and the probabilities resulting from $m+1$ iteration were allocated to vector $\mathbf{p}_{2} ;$

5. The sum of squared deviations between $p_{4}$ and $\mathbf{p}_{2}$ was calculated, this value was saved as $d_{K}$;

6. The values were updated as $\mathbf{p}_{4}=\mathbf{p}_{2}, m=m+1$;

7. Steps 4 to 6 were repeated until the value of $d_{k}$-was sufficiently close to zero.

A selection of the results from this process is presented in Figure 2. It is evident that The convergence in the value of probabilities occurs occurred with about 200 iterations of the Monte Carlo simulation of the DPRD model, and this was the number of iterations used to generate the TPMs.

Insert Figure 2 near here

\section{Results}

The optimal solutions, $\mathbf{u}^{s *}\left(\mathbf{z}^{s}\right)$, for any initial state of the pasture resource were identified by solving the SDP model. For any given fertiliser input level, a total of 4000 optimal selutions-decisions exist that describe the optimal stocking rate and pasture renovation policy for each of the 1000 initial states and 4 seasons. Due to the size of the output dataset, the majority of results are presented through the calculation of long-run probabilities and expected eptimal target levelsvalues for the states that 
describe quantity and quality of the pasture resource, and by summarising the states that induce certain decisions, such as tactical grazing rests and pasture renovation.

\subsection{Optimal decision variables}

The optimal stocking rate or pasture re-sow decision varies with season and the state of the pasture.

The distribution of optimal decisions for each initialall combinations of pasture state, within each season and soil fertility input system is are presented in Figure 2 . The initial state of the pasture is defined as pasture mass at the start of the season $(Y c)$ on the y-axis and the proportion of desirables $(x)$ that occupy the sward at the start of the season on the x-axis. Given the dimensions of the SDP outputs, these smoothed decision variable contour plots allow identification of trends in the optimal decision vector and provide a quick means of locating optimal decisions by finding corresponding initial pasture state coordinates.

\section{Insert Figure 2 near here}

Figure 2 simplifies the presentation of the 4000 optimal selutiensdecisions. The white areas within each chart indicate the states of pasture condition when the optimal decision was to re-sow the pasture at the start of a season. The optimal stocking rate decisions were aggregated into 6 groups, ranging from a tactical seasonal grazing rest (0 DSE/ha) to very high stocking rates (40 DSE/ha) over a season, and are represented by other colours. Figure 2 illustrates that the highest stocking rates across all proportions of desirables are maintained in spring, whereas the lowest stocking rates are maintained in winter and summer.

Within each season the pattern of distribution of optimal decisions tend to be consistent across different soil fertility input systems. However, as soil fertility increases, so does the optimal stocking rate. The pasture states where complete seasonal grazing rest is optimal (a stocking rate of $0 \mathrm{hd} / \mathrm{ha}$ ) occur predominately during summer, especially under low soil fertility conditions (Figure $2 d$ ). This decision tends to become optimal when very low pasture mass conditions of less than $500 \mathrm{~kg} \mathrm{DM} / \mathrm{ha}$ exist at the start of summer. Very low seasonal stocking rates (a stocking rate of $2 \mathrm{hd} / \mathrm{ha}$ ) tend to be optimal during summer and winter, and to a lesser extent in autumn, when pasture mass is low (less than 1000kg $\mathrm{DM} / \mathrm{ha}$ ). During winter, as the proportion of desirables in the pasture decline, the pasture mass under which low seasonal stocking rates are optimal increases. This especially occurs under moderate and high soil fertility systems (Figure $2 f$ and $j$ ), which clearly indicates the optimal use of lower seasonal stocking rates at lower proportions of desirables (from 0.1 to 0.4 ), rather than the re-sowing of pasture. 
The decision to invest in pasture renovation tends to become the most profitable decision during winter and autumn. It occurs under all soil fertility input systems, however, as soil fertility increases during winter (Figure $2 f$ and $j$ ), a clearer delineation occurs at around 0.15 desirables, where less than this proportion of desirables triggers the optimal re-sow decision regardless of pasture mass.

3.2 Optimal trajectoriesLong-run distributions under optimal management for different input systems

The optimal decisions identified through the SDP process were used to derive long-run (stationary) probabilities as explained in the Methods section. Univariate cumulative distributions for both pasture biomass and the proportion of desirables are shown in Figure 3Figure 3 for all seasons under the three $\underline{\text { soil fertility input systems. The joint probability distributions corresponding to these results are }}$ presented in the online supplementary materials.

The optimal solutions for any initial state of the pasture resource are used to demonstrate a time sequence of optimal states, based on the state transition probabilities and expected state values (see equation 12). The sequences of optimal states have been calculated and plotted for four diverse initial pasture states under each input system from the start of autumn (Figure 4). These values represent the expected values that result from the long term state probabilities when the system is managed according to the optimal decision rule. The convergence of seasonal values that define the pasture resource $\theta$ are the expected optimal target levels of pasture mass and proportion of desirables for each seasen.

\section{Insert Figure 3 near here}

As would be expected in the case study region (Behrendt et al., 2013c), winter-pasture biomass at the $\underline{\text { start of winter exhibited consistently the lowest range of values amongst all four seasonal distributions, }}$ and across all soil fertility input systems. Autumn and spring were found to be similar, with sSummer maintaininged the highestlargest distribution of pasture biomass in the long run, whereas autumn and spring were found to be similar. Figure 3 indicates that with increasing soil fertility inputs, the expected value for pasture mass in each season increases. Although it is noticeable that winter experiences only a small increase in the mean pasture mass, whereas autumn, spring and in particular summer, experience much larger increases in this variable.

Under a low soil fertility input system (Figure $3 b$ ) the long run distributions for the proportion of desirables indicate that it is the lowest during summer and the highest during spring. Autumn and 
489

490

winter maintain similar distributions to those for moderate and high soil fertility input systems, albeit with noticeably lower expected values. As soil fertility input increases, the distribution of desirables between seasons becomes more balanced (Figure $3 d$ and $f$ ), although still maintaining similar patterns to those of low soil fertility systems. The trajectories of the proportion of desirables in both the low and moderate input systems (Figure $4 \mathrm{a}$ and $b$ ) show that, at a pasture state of $900 \mathrm{~kg}$ DM/ha and 0.15 desirables, the optimal decision was to re-sow the pasture, hence its increase to 0.95 desirables in the second season. For this initial state, under the high input system, the expected optimal decisions were a combination of tactical seasonal grazing rests $(0 \mathrm{hd} / \mathrm{ha})$ and reduced grazing pressure to allow both the amount of pasture mass and proportion of desirables to increase towards optimal target levels.

For the pasture states with $2500 \mathrm{~kg}$ DM/ha and either 0.15 or 0.75 desirables, the optimal decisions were to keep utilising the pastures, albeit at different stocking rates. For the state with 0.15 desirables under all input systems, stocking rates were adjusted to reduce the pasture mass to optimal target levels whilst concurrently increasing the propertion of desirables up to optimal target levels. For the initiat state with 0.75 desirables and $2500 \mathrm{~kg} \mathrm{DM} / \mathrm{ha}$, the highest expected stocking rates were maintained during the period of convergence as the condition of the pasture resource moved downward towards the eptimal target state.

Convergence of botanical composition indicated that, under a low soil fertility system, the identified optimal decision would direct the state of the pasture resource towards maintaining around $40 \%$ desirables in the sward. This inereased to $50 \%$ and $60 \%$ for the moderate and high seil fertility systems respectively.

Figure 4 also illustrates the optimal stocking rate decisions that were implemented to maximise the expected present value and direct the state of the system towards its optimal state. The optimal trajectories followed a seasonal pattern for pasture mass and stocking rate. Table 4 details the state of the pasture resource at policy convergence, which defines the expected optimal target levels for management to maximise the economically sustainable yields from the pasture resource.

\section{Insert Table-4 near here}

Optimal target levels for pasture mass ranged from $906 \mathrm{~kg}$ DM/ha during winter in the low input system, to $2231 \mathrm{~kg}$ DM/ha during summer in the moderate input system. On average, the highest target pasture mass was maintained in summer, closely followed by spring, autumn and winter. These end-ofseasen optimal pasture mass targets tended to increase with increasing soil fertility in autumn, winter 
and spring. For summer, the optimal expected pasture mass peaked under a moderate input system, but at a lower proportion of desirables than under the high input system $(0.47$ versus 0.57$)$.

Increasing discount rates resulted in minimal changes in the long run distributions and mean values of either pasture mass or the proportion of desirables reduction in the optimal target level of desirable species in the sward by a small amount (Figure 5)(Table 4). There is some indication that increasing the discount rate, to well above what would be typically used in industry, leads to a slight reduction in the mean amount of pasture biomass across all seasons, with the proportion of desirables in the long-run expected to increase during spring. The changes in optimal target levels of pasture mass, proportion of desirables and stocking rates in respense to changes in discount rates between $3 \%$ and $10 \%$, were negligible. However, when examining optimal stocking rate and re-sow decisions via contour plots for each season and discount rate (not shown), there were subtle differences in the optimal stocking rate policies at lower levels of desirables in the sward. This indicated that, with higher discount rates, higher stocking rates were optimal at lower proportions of desirables, which is consistent with the data presented in Table 4. In addition, with lower discount rates, the states of pasture where the re-sow decision was optimal increased in winter and autumn.

\section{Insert Table 4 near here}

\section{Discussion}

The results of the seasonal SDP model presented illustrate how the bioeconomic framework developed can be used to identify optimal tactical and strategic decisions in the management of livestock within a dynamic pasture resource under stochastic climatic conditions. The decision variables applied in this research are the strategic maintenance of soil fertility through the regular application of fertiliser, the strategic sowing of introduced species, and the tactical use of grazing management to utilise the pasture resource and manipulate botanical composition. The optimal decisions identified balance the economic returns from the present utilisation of the pasture with the long-term inter-temporal dynamic benefits and costs of maintaining a desirable botanical composition.

$\underline{\text { The relationship reported between botanical composition, pasture biomass and profit over an infinite }}$ planning horizon, which is embedded within the identified optimal decisions (Figure 2), is a reflection of sustainable exploitation of the pasture resource that can occur over the long term. When a pasture $\underline{\text { state exists which represents a high proportion of desirables in the sward, exploitation or increased }}$ 
549

550

551

552

utilisation of the pasture resource and the desirable population through the application of high stocking rates would be expected to increase profits in the short run and cause the system to transition towards a state with a lower proportion of desirables and reduced levels of available pasture biomass over the long run. However, when sub-optimal levels of desirables exist in the sward, the optimal decision rules, through either reduced stocking rates or capital investment in re-sowing of the pasture, would be expected to transition the pasture towards a state with a higher proportion of desirables and increased amounts of available pasture biomass in the long run, but with reduced profitability in the short run.

The use of tactical grazing rests has been recommended as a means of maintaining a higher proportion of desirable species (Michalk et al., 2003). Our framework allows guidelines for triggering seasonal grazing rests to be identified. An alternative to complete grazing rest is the application of low stocking rates (less than $5 \mathrm{hd} / \mathrm{ha}$ ), which was frequently optimal at states with low levels of pasture mass and desirables. This especially occurred in winter when there were less than $30 \%$ desirables in the sward. Autumn and winter were the seasons in which re-sowing of pastures occurred the most, which corresponds to predicted optimum times of sowing pastures in the New England Tablelands (Dowling and Smith, 1976). However, the re-sowing of pastures in summer and spring was also considered optimal under very degraded pasture states (5-15\% desirables and less than $1000 \mathrm{~kg}$ DM/ha pasture mass). On agronomic principles this may not be optimal and reveals a limitation of the model, as the strategic decision of re-sowing is available at each seasonal decision stage.

Significant differences existed in the digestibility of the pasture on offer due to changes in the proportion of desirables in the sward. This in turn influenced the levels of livestock production the pasture is capable of sustaining. This can be seen in the relationship between different states of pasture mass and the proportion of desirables, and the optimal stocking rate decision. The results suggest that, although different input systems would optimally maintain similar levels of pasture mass within seasons, the critical difference in determining livestock production and profit is the proportion of desirables in the sward. This is in part due to the high amount of summer production from the modelled undesirable species, that is, Bothriochloa macra (red grass), which is known to produce feed of low quality. This is supported by data from the Northern Tablelands which showed the total production of Bothriochloa macra to be similar to that of phalaris but with significantly different growth patterns as well as greater stem to leaf ratios and lower dry matter digestibilities (Robinson and Archer, 1988). 
Interacting with this relationship is the sequence of utilisation of the pasture resource by animals. For the case study, lower stocking rates were optimal in winter and summer, which allowed higher stocking rates during autumn and spring (Figure 2). These are periods where the desirable species within the sward maintain highly digestible pasture dry matter and enable higher levels of production. This reinforces the importance of considering the differences in pasture quality between the desirable and undesirable components of the sward in determining livestock production and the optimal development and management of the pasture resource.

\subsection{Optimal-Long-run botanical composition under optimal management}

Results suggest that the expected long-run proportion of desirables in the sward varies with soil fertility and season, with overall annual mean values ranging between 0.43 and 0.49 . These are significantly higher levels than those of the average producer in the high rainfall temperate pasture zone of Australia (Dellow et al., 2002). This potentially indicates that sub-optimal grazing management and pasture $\underline{\text { renovation practices are being applied in industry. }}$

Increasing soil fertility was found to lead to long-run distributions where there is a greater proportion of desirables in the summer, and all year round, as higher soil fertility input systems are known to be capable of maintaining a higher level of desirables in pasture swards (Cook et al., 1978a; Hill et al.,

2004). As soil fertility increases, the expected mean proportion of desirables in the long run increases by around $10 \%$ under the moderate and high input systems relative to the low-input system. These levels of desirables in the sward correspond to those found by Jones et al. (2006). In this case study, $\underline{B o t h r i o c h l o a ~ m a c r a ~ a n d ~ a n n u a l ~ g r a s s e s ~ s u c h ~ a s ~ V u l p i a ~ s p p ., ~ w h i c h ~ d e f i n e ~ t h e ~ u n d e s i r a b l e ~ s p e c i e s, ~}$ contributed significantly to the feed base for the wool-dominated livestock production system. The fact $\underline{\text { that they are labelled 'undesirables' does not detract from their value as a feed source and they are as }}$ important as desirables in determining the distribution of long-run pasture states (Behrendt, 2008; Behrendt et al., 2013a).Results suggest that the optimal pasture state depends on the level of soil fertility. The optimal target proportion of desirables in the sward varied with soil fertility between 0.40 and 0.60. These levels were significantly higher than the average for producers in the high rainfall temperate pasture zone of Australia (Dellow et al., 2002; Kemp and Dowling, 1991) and potentially indicates sub-optimal grazing management and pasture renovation practices are being applied in industry. 
607

The lower optimal proportions of desirables occur under the low soil fertility system, with the ability of this low input system to maintain a higher level of desirables limited by the lack of fertiliser inputs (Cook et al., 1978a; Hill et al., 2004). As soil fertility increases, the optimal proportion of desirable species increases by $10 \%$ and $20 \%$ under the moderate and high input systems. These levels of desirables in the sward correspond to those found by Jones et al. (2006). In this case study, Bothriochloa macra and annual grasses such as Vulpia spp., which define the undesirable species, contributed significantly to the feed base for the wool-dominated livestock production system. The value of undesirable species is equally important in determining optimal pasture states, which has also been shown to be influenced by the type of livestock production system and its emphasis on meat or wool production (Behrendt, 2008; Behrendt et al., 2013a).

The relationship reported between botanical composition and profit is a reflection of sustainable exploitation of the pasture resource that can occur and the time that it takes for the system to reach eptimal states of pasture mass and betanieal compesition. When the initial pasture state represents a high proportion of desirables in the sward, exploitation of the pasture resource and the desirable population caused the system to move towards its lower optimal state. When sub-optimal levels of desirables existed in the sward, the pasture resomree was improved through either reduced stocking rates or capital investment in re-sowing of the pasture.

The use of tactical grazing rests has been recommended as a means of maintaining a higher proportion of desirable species (Michalk et al, 2003). Our framework allows guidelines for triggering seasenal grazing rests to be identified. An alternative to complete grazing rest is the application of low stocking rates (less than $5 \mathrm{hd} / \mathrm{ha}$ ), which was frequently optimal at pasture states with low levels of pasture mass and desirables. This especially occurred in winter when there were less than $30 \%$ desirables in the sward.

Autumn and winter were the seasons in which re-sowing of pastures occurred the most, which corresponds to predicted optimum times of sowing pastures in the New England Tablelands (Dowling and Smith, 1976). However, the re-sowing of pastures in summer and spring was also considered eptimal under very degraded pastmre states (5 15\% desirables and less than $1000 \mathrm{~kg}$ DM/ha pastmre mass). On agronomic principles this may not be optimal and reveals a limitation of the model, as the strategic decision of re-sowing is available at each seasonal decision stage. 
637

638

The results indicate that eptimal targetthe long-run distributions of pasture mass under optimal management vary to achieve maximum sustainable economic yields vary with season and soil fertility. In this case study their expected values levels-were noticeably higher for autumn, spring and summer than those suggested by field research as being required for the persistence of sown species (Avery et al., 2000; Dowling et al., 1996), for the persistence of desirable grasses on the Central Tablelands of NSW (Michalk et al., 2003), and to maintain groundcover targets of $80 \%$ (Lilley and Moore, 2009). but are similar to those required for the persistence of desirable grasses on the Central Tablelands of NSW (Michalk et al., 2003). This indicates that producers in the case study region should-would maintain higher pasture masses, if abiding by the optimal decision rules, than those typically recommended as minimum pasture benchmarks for livestock production (Bell and Blackwood, 1993). In contrast the long run distribution of pasture biomass during winter is relatively low and more typical of industry practice (Scott et al., 2013). If a minimum of $500 \mathrm{~kg} \mathrm{DM} / \mathrm{ha}$ of high quality pasture is required to maintain a dry sheep during winter (Bell and Blackwood, 1993), in the long run, low fertility systems are expected to be below this state $74 \%$ of the time. Whereas increasing soil fertility reduces the expected long run occurrence of this state to $53 \%$ and $43 \%$ of the time under moderate and high fertility input systems. This aligns with the typical feeding requirements and practices of sheep producers in the case study region (Scott et al., 2013).

\subsection{Sensitivity to discount rate}

Significant differences existed in the digestibility of the pasture on offer due to changes in the proportion of desirables in the sward. This in turn influenced the levels of livestock production the pasture is capable of sustaining. This can be seen in the relationship between pasture mass, the proportion of desirables and stocking rate. The results suggest that, although different input systems would optimally maintain similar levels of pasture mass within seasons, the critical difference in determining livestock production and profit is the proportion of desirables in the sward. This is in part due to the high amount of summer production from the modelled undesirable species, that is, Bothriochloa macra (red grass), which is known to produce feed of low quality. This is supported by data from the Northern Tablelands which showed the total production of Bothriochloa macra to be similar to that of phalaris but with significantly different growth patterns as well as greater stem to leaf ratios and lower dry matter digestibilities (Robinson and Archer, 1988). 
$\mid \begin{aligned} & 666 \\ & 667 \\ & 668 \\ & 669 \\ & 670 \\ & 671 \\ & 672\end{aligned}$

Interacting with this relationship is the sequence of how the pasture resource is utilised. For the case

study, lower stocking rates were optimal in winter and summer, which allowed higher stocking rates during autumn and spring. These are periods where the desirable species within the sward maintain highly digestible pasture dry matter and enable higher levels of production. This reinforces the impertance of the differences in pasture quality between the desirable and undesirable compenents of the sward in determining livestock production and the optimal development and management of the pasture resource.

The sensitivity analysis of optimal decisions to the discount rate suggested optimal stocking rate and re-sowing polices were robust across a broad range of discount rates. The reason for this was that increased stocking rates and the re-sow decision were antagonistic policies in terms of maximising present value. Under high discount rates, there was an increasing emphasis on higher stocking rates to lift pasture resource utilisation and maximise returns in the short term. This was, however, limited by the cost of sowing and the opportunity cost of not grazing during the establishment period under high discount rates.

\section{Conclusions}

The SDP model identified the optimal seasonal stocking rate and pasture sowing polices for each type of soil fertility input system under the assumption that the objective of the decision maker is to maximise the expected present value of future returns. These optimal policies were derived within a framework where the risks from a stochastic climate are embedded into the decision-making process. From the application of these optimal decisions the expected optimal state of the pasture resource was defined in terms of pasture mass and botanical composition. Long-run probabilities of total pasture mass and the proportion of desirables under optimal management were examined to construct expected outcomes over an infinite planning horizon.

The extrapolation of the results from this research to other regions with confidence is difficult due to a significant number of interrelating variables and parameters. Differences in climate, soil type, topography and the species that make up the pasture would influence the optimal decision vector. The relative differences in quality and seasonal growth patterns of the different species groups would influence the optimal target levels of desirable species and the optimal stocking rates to achieve these levels. Differences in the rate of botanical change responses of the desirable species population to tactical grazing rests, soil fertility and livestock harvesting also affects the long term dynamics of the 
pasture resource. However, the ability of the framework to adjust the optimal decision vector in response to these variables and parameters enables its application in a broad range of situations. Given all grasslands are subject to botanical composition change, whether grazed by transient herbivores or domesticated livestock, the bioeconomic framework described is broadly applicable. The most significant challenge in applying the model to systems in other geographical areas is the calibration of pasture production and botanical composition change parameters, which ideally should be based on experimental data.

The identified optimal decisions are broadly applicable to other paddocks within a farming system that maintain similar species within its-their desirable and undesirable groups. The seasonal stocking rate contour plots provided a visual guide to a large range of optimal decisions for different states of the pasture resource in each season. Conceptually, the application of this tool could be used to help guide a producer or advisor in deciding the optimal management of a paddock at the start of a season.

The time frame for decision making regarding pasture development has been suggested to be 10-15 years for profit maximisation and 20-30 years for the sustainability and persistence of the pasture system (Lodge et al., 1998; Scott and Lovett, 1997). A key feature of the optimal decision rules that were derived using this bioeconomic framework is that they remain optimal regardless of the time frame being considered, as they represent an infinite planning horizon. An interesting outcome is that the discount rate only had a small effect on optimal decision rules, because of the antagonism between the benefits of higher stocking rates and the costs of replacing overgrazed pastures.

The optimal target levels-optimal long-run distributions and their expected values indicate a-the states of the pasture resource which corresponds to that of the maximum economic sustainable yield, whereby the pasture is viewed as an exploited renewable resource (Clark, 1990). This sustainable state is based on the objective of profit maximisation, but is constrained by the impact of livestock harvesting on the desirable plant population, the concurrent impacts on the productivity of the grazing system, and the capital cost of resource renewal.

A key feature of this study was the embedding of production risk into the pasture development decision-making problem with the incorporation of a dynamic botanical composition model. The benefit of this approach is that it considers the inter-temporal trade-offs between investments in pasture development and the utilisation of the pasture resource under climatic uncertainty. The study has 
shown how we can more realistically model the complex decision process which faces livestock producers and thereby provide readily transferable information to improve decision making.

\section{Acknowledgments}

The authors wish to thank the members, team and board of The Cicerone Project for making data available, in particular the contribution of Libuseng Shakhane, Caroline Gaden, Justin Hoad, Colin Lord and Dion Gallagher. Support received from the CSIRO Plant Industry group, in particular Andrew Moore and Libby Salmon, is also gratefully acknowledged.

\section{References}

ABARE, 2006. Australian Commodity Statistics 2006. Australian Bureau of Agricultural and Resource Economics, Canberra.

Antle, J.M., 1983. Incorporating Risk in Production Analysis. American Journal of Agricultural Economics 65, 1099-1106.

Avery, A.L., Michalk, D.L., Thompson, R.P., Ball, P., Prance, T., Harris, C.A., FitzGerald, D.W., Ayres, J.F., Orchard, B.A., 2000. Effects of sheep grazing management on cocksfoot herbage mass and persistence in temperate environments. Australian Journal of Experimental Agriculture 40, 185-206.

Behrendt, K., 2008. Bioeconomics of pasture resource development in sheep production systems. The University of New England, Armidale, p. 215.

Behrendt, K., Cacho, O., Scott, J.M., Jones, R., 2013a. Optimising pasture and grazing management decisions on the Cicerone Project farmlets over variable time horizons. Animal Production Science 53, 796-805.

Behrendt, K., Scott, J.M., Cacho, O., Jones, R.E., 2013b. Simulating the impact of fertiliser strategies and prices on the economics of developing and managing the Cicerone Project farmlets under climatic uncertainty. Animal Production Science 53, 806-816.

Behrendt, K., Scott, J.M., Mackay, D.F., Murison, R., 2013c. Comparing the climate experienced during the Cicerone farmlet experiment against the climatic record. Animal Production Science 53, 658-669.

Bell, A., Blackwood, I., 1993. Pasture Benchmarks for sheep and cattle production, in: Michalk, D.L. (Ed.), Proceedings of the Eighth Annual Conference of the Grassland Society of NSW, Orange, pp. 2528. 
Cacho, O., 1998. Solving bioeconomic optimal control models numerically, in: Gooday, J. (Ed.), Proceedings of the bioeconomics workshop. Post-Australian Agricultural and Resource Economics Society conference, University of New England, Armidale, New South Wales. Australian Bureau of Agricultural and Resource Economics (ABARE), Canberra, Canberra Australia, pp. 13-26.

Cacho, O., Finlayson, J.D., Bywater, A.C., 1995. A simulation model of grazing sheep: I. Whole farm model. Agricultural Systems 48, 27-50.

Cacho, O.J., 1993. A practical equation for pasture growth under grazing. Grass and Forage Science 48, 387-394.

Cacho, O.J., Bywater, A.C., Dillon, J.L., 1999. Assessment of production risk in grazing models. Agricultural Systems 60, 87-98.

Clark, C.W., 1990. Mathematical bioeconomics: the optimal management of renewable resources, 2nd Edition ed. John Wiley and Sons Inc., New York USA.

Colwell, J.D., 1963. The estimation of the phosphorus fertilizer requirements of wheat in southern New South Wales by soil analysis. Australian Journal of Experimental Agriculture and Animal Husbandry 3 , 190-197.

Cook, S., Blair, G., Lazenby, A., 1978a. Pasture degeneration. II. The importance of superphosphate, nitrogen and grazing management. Australian Journal of Agricultural Research 29, 19-29.

Cook, S., Lazenby, A., Blair, G., 1978b. Pasture degeneration. I. Effect on total and seasonal pasture production. Australian Journal of Agricultural Research 29, 9-18.

CSIRO, 2007. AusFarm, in: CSIRO (Ed.), Version 1.3.2 ed. CSIRO Plant Industry, Canberra. Davies, L., 2005. Using DSEs and carrying capacities. NSW Department of Primary Industries, Orange.

Dellow, J.J., Wilson, G.C., King, W.M., Auld, B.A., 2002. Occurrence of weeds in the perennial pasture zone of New South Wales. Plant Protection Quarterly 17, 12-16.

Dowling, P.M., Kemp, D.R., Ball, P.D., Langford, C.M., Michalk, D.L., Millar, G.D., Simpson, P.C., Thompson, R.P., 2005. Effect of continuous and time-control grazing on grassland components in south-eastern Australia. Australian Journal of Experimental Agriculture 45, 369-381.

Dowling, P.M., Kemp, D.R., Michalk, D.L., Klein, T.A., Millar, G.D., 1996. Perennial Grass Response to Seasonal Rests in Naturalised Pastures of Central New South Wales. The Rangeland Journal 18, 309-326. 
Dowling, P.M., Smith, R.C.G., 1976. Use of a soil moisture model and risk analysis to predict the optimum time for the aerial sowing of pastures on the Northern Tablelands of New South Wales. Australian Journal of Experimental Agriculture and Animal Husbandry 16, 871-874.

Freer, M., Dove, H., Nolan, J.V., 2007. Nutrient Requirements of Domesticated Ruminants, in: Freer, M., Dove, H., Nolan, J.V. (Eds.), Feeding Standards for Australian Livestock: Ruminants. CSIRO Publishing, Collingwood, p. 270.

Garden, D.L., Lodge, G.M., Friend, D.A., Dowling, P.M., Orchard, B.A., 2000. Effects of grazing management on botanical composition of native grass-based pastures in temperate south-east Australia. Australian Journal of Experimental Agriculture 40, 225-245.

Godden, D.P., Helyar, K.R., 1980. An alternative method for deriving optimal fertilizer rates. Review of Marketing and Agricultural Economics 48, 83-97.

Guppy, C.N., Edwards, C., Blair, G.J., Scott, J.M., 2013. Whole-farm management of soil nutrients drives productive grazing systems: the Cicerone farmlet experiment confirms earlier research. Animal Production Science 53, 649-657.

Hardaker, J.B., Pandey, S., Patten, L.H., 1991. Farm Planning under uncertainty: A review of Alternative Programming Models. Review of Marketing and Agricultural Economics 59, 9-22. Hill, J.O., Simpson, R.J., Moore, A.D., Graham, P., Chapman, D.F., 2004. Impact of phosphorus application and sheep grazing on the botanical composition of sown pasture and naturalised, native grass pasture, Australian Journal of Agricultural Research, pp. 1213-1225

Hutchinson, K.J., 1992. The Grazing Resource, in: Hutchinson, K.J., Vickery, P. (Eds.), Proceedings 6th Australian Society of Agronomy Conference, UNE, Armidale, pp. 54-60.

Jones, R.E., Dowling, P.M., Michalk, D.L., King, W.M., 2006. Sustainable grazing systems for the Central Tablelands of New South Wales. 5. A bioeconomic framework for assessing the long-term economic benefits of grazing management tactics and implications for sustainability. Australian Journal of Experimental Agriculture 46, 495-502.

Jones, R.M., Jones, R.J., McDonald, C.K., 1995. Some advantages of long-term grazing trials, with particular reference to changes in botanical composition. Australian Journal of Experimental Agriculture 35, 1029-1038.

Kemp, D., Dowling, P., 1991. Species distribution within improved pastures over central N.S.W. in relation to rainfall and altitude. Australian Journal of Agricultural Research 42, 647-659. 
Kennedy, J.O.S., 1986. Dynamic Programming - Applications to Agriculture and Natural Resources.

Elsevier, Amsterdam.

Lilley, J.M., Moore, A.D., 2009. Trade-offs between productivity and ground cover in mixed farming systems in the Murrumbidgee catchment of New South Wales. Animal Production Science 49, $837-$ 851

Lodge, G., Scott, J.M., King, K.L., Hutchinson, K.J., 1998. A review of sustainable pasture production issues in temperate native and improved pastures, Animal Production in Australia. Proceedings of the Australian Society of Animal Production. Australian Society of Animal Production, pp. 79-89.

Loewer, O.J., 1998. GRAZE: A Beef-Forage Model of Selective Grazing, in: Peart, R.M., Curry, B.R. (Eds.), Agricultural Systems Modeling and Simulation. Marcel Dekker, Inc., New York, pp. 301-418. Marshall, G.R., Randall, E.J., Wall, L.M., 1997. Tactical opportunities, risk attitude and choice of farming strategy: an application of the distribution method. The Australian Journal of Agricultural and Resource Economics 41, 499-519.

Mathworks_Inc, 2013. R2013b(Version 8.2). The Mathworks Inc., Massachusetts.

McLeod, M.K., Cresswell, H.P., MacLeod, D.A., R.D., F., H., D., 1998. Measurement of Evapotranspiration from Different Pasture Types Using the Rapid Chamber Method, in: Michalk, D.L. (Ed.), Proceedings of the 9th Australian Agronomy Conference. Australian Society of Agronomy,

Wagga Wagga.

Michalk, D.L., Dowling, P.M., Kemp, D.R., King, W.M., Packer, I.J., Holst, P.J., Jones, R.E., Priest, S.M., Millar, G.D., Brisbane, S., Stanley, D.F., 2003. Sustainable grazing systems for the Central Tablelands, New South Wales. Australian Journal of Experimental Agriculture 43, 861-874.

Robinson, G.G., Archer, K.A., 1988. Agronomic potential of native grass species on the Northern Tablelands of New South Wales. I. Growth and herbage production. Australian Journal of Agricultural Research 39, 415-423.

Scott, J.M., Gaden, C.A., Edwards, C., Paull, D.R., Marchant, R., Hoad, J., Sutherland, H., Coventry, T., Dutton, P., 2013. Selection of experimental treatments, methods used and evolution of management guidelines for comparing and measuring three grazed farmlet systems. Animal Production Science 53, 628-642.

Scott, J.M., Lovett, J.V., 1997. Pastures in sustainable systems, in: Scott, J.M., Lovett, J.V. (Eds.), Pasture Production and Management. Elsevier Australia, Marrickville, pp. 269-276. 
Shakhane, L.M., Mulcahy, C., Scott, J.M., Hinch, G.N., Donald, G.E., Mackay, D.F., 2013a. Pasture herbage mass, quality and growth in response to three whole-farmlet management systems. Animal Production Science 53, 685-698.

Shakhane, L.M., Scott, J.M., Murison, R., Mulcahy, C., Hinch, G.N., Morrow, A., Mackay, D.F., 2013b. Changes in botanical composition on three farmlets subjected to different pasture and grazing management strategies. Animal Production Science 53, 670-684.

Stafford Smith, D.M., Milham, N., Douglas, R., Tapp, N., Breen, J., Buxton, R., McKeon, G., 1995. Whole Farm Modelling and Ecological Sustainability: a Practical Application in the NSW Rangelands, Ecological Economics Conference, Coffs Harbour, NSW, November 19 to 23, 1995 : Conference Papers. Australia \& New Zealand Society for Ecological Economics in Association with the Centre for Agricultural and Resource Economics, Coffs Harbour, pp. 243-249.

Torell, L.A., Lyon, K.S., Godfrey, E.B., 1991. Long-Run versus Short-Run Planning Horizons and the Rangeland Stocking Rate Decision. American Journal of Agricultural Economics 73, 795-807.

Trebeck, D.B., Hardaker, J.B., 1972. The integrated use of simulation and stochastic programming for whole farm planning under risk. Australian Journal of Agricultural Economics 16, 115-126.

Westoby, M., Walker, B., Noy-Meir, I., 1989. Opportunistic management for rangelands not at equilibrium. Journal of Range Management 42, 266-274.

Woodward, S.J.R., 1996. A Dynamic Nutrient Carryover Model for Pastoral Soils and Its Application to Optimising Fertiliser Allocation to Several Blocks with a Cost Constraint. Review of Marketing and Agricultural Economics 64, 75-85. 


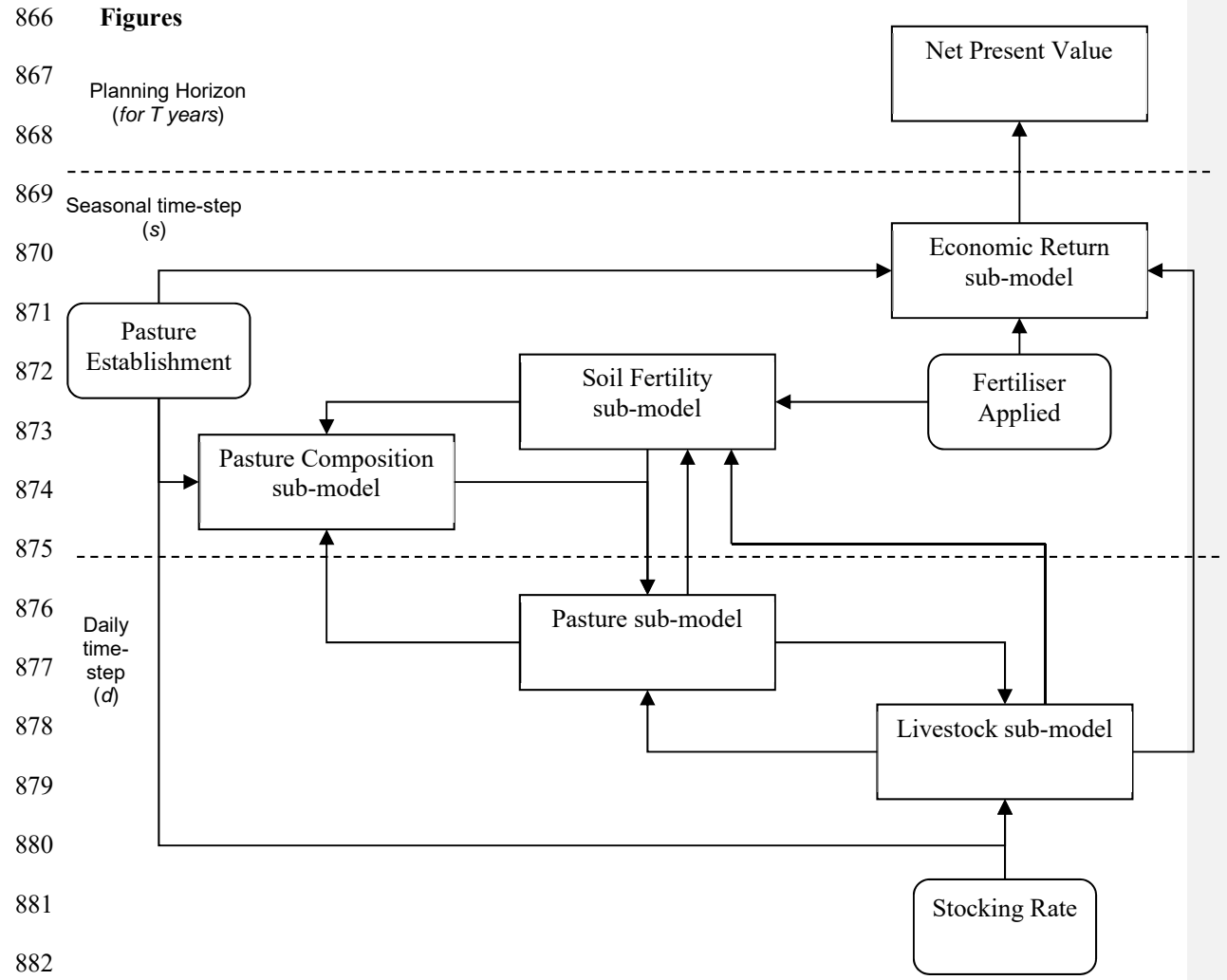

Figure 1: A diagrammatic outline of the Dynamic Pasture Resource Development simulation model at the paddock level (Behrendt et al., 2013b).

885

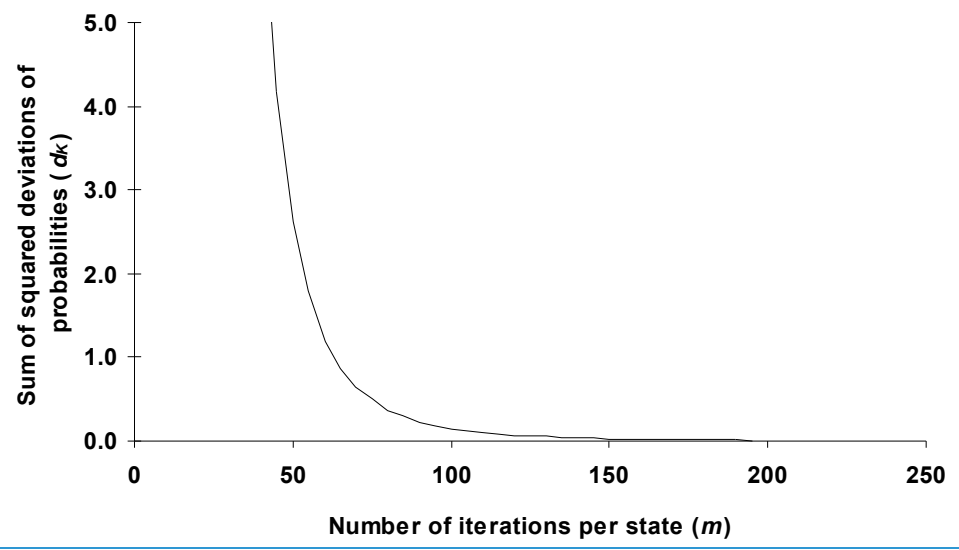



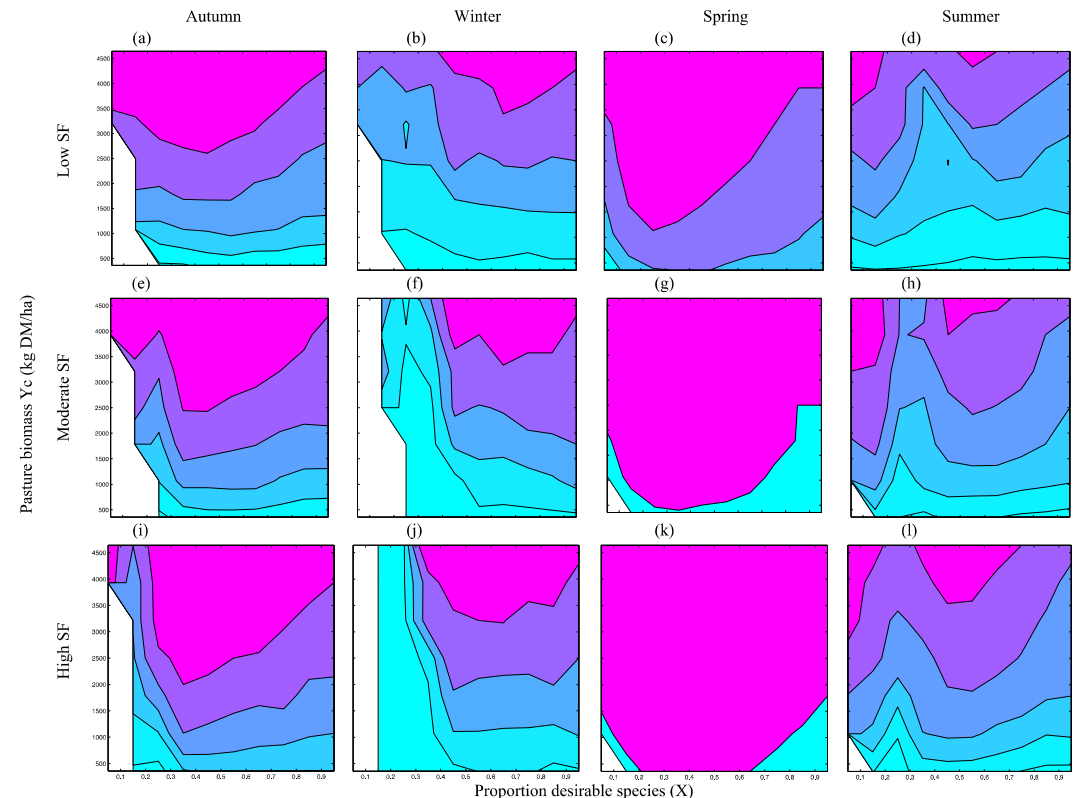

Figure 2: Smoothed optimal stocking rate and re-sow contour plots showing the relationship between the state of the pasture resource (in terms of season, pasture mass and proportion of desirables at the beginning of the season) on the mean optimal decision, being either the seasonlong stocking rate decision or re-sow decision, for a paddock with different fertiliser input systems (SF). The mean optimal decision contours represent the decision variables of pasture resowing ( $\square$ ), grazing rest ( $\square$ ), mean sr of 2 ( $\square$ ), 8 ( $\square$ ), 15 ( $\square$ ), 25 ( $\square$ ) and 40 DSE/ha ( $\square$ ). 


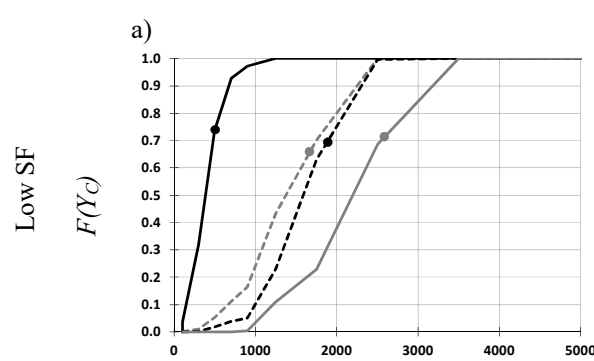

c)

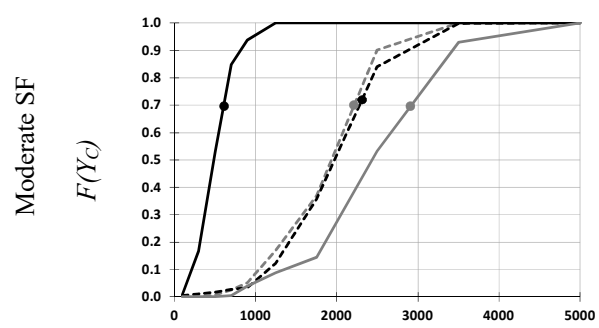

e)

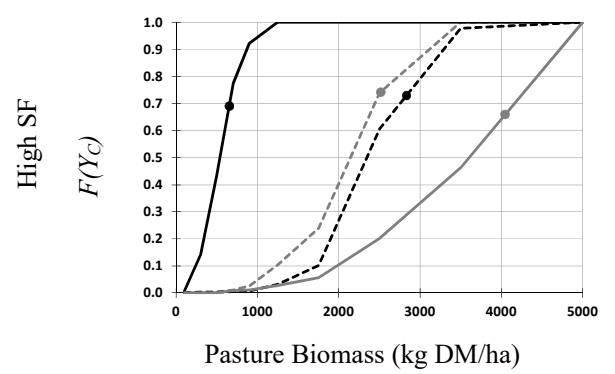

b)

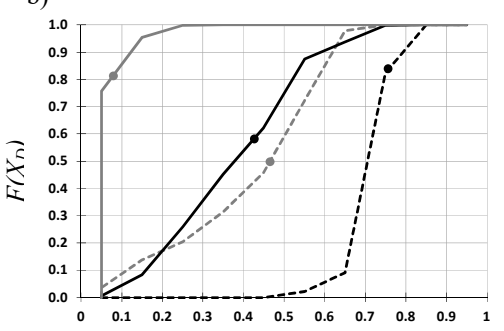

d)

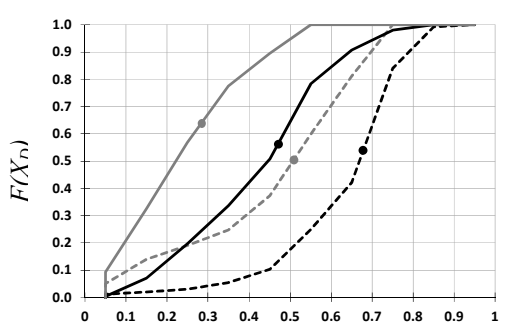

f)

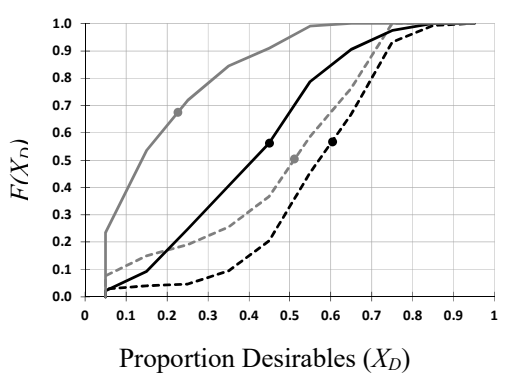

899
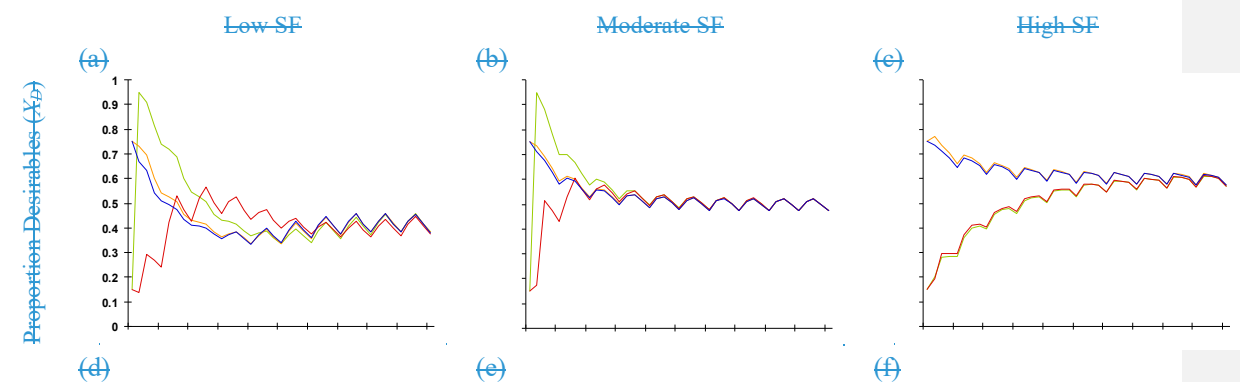

(d)

(e)

(丹) 

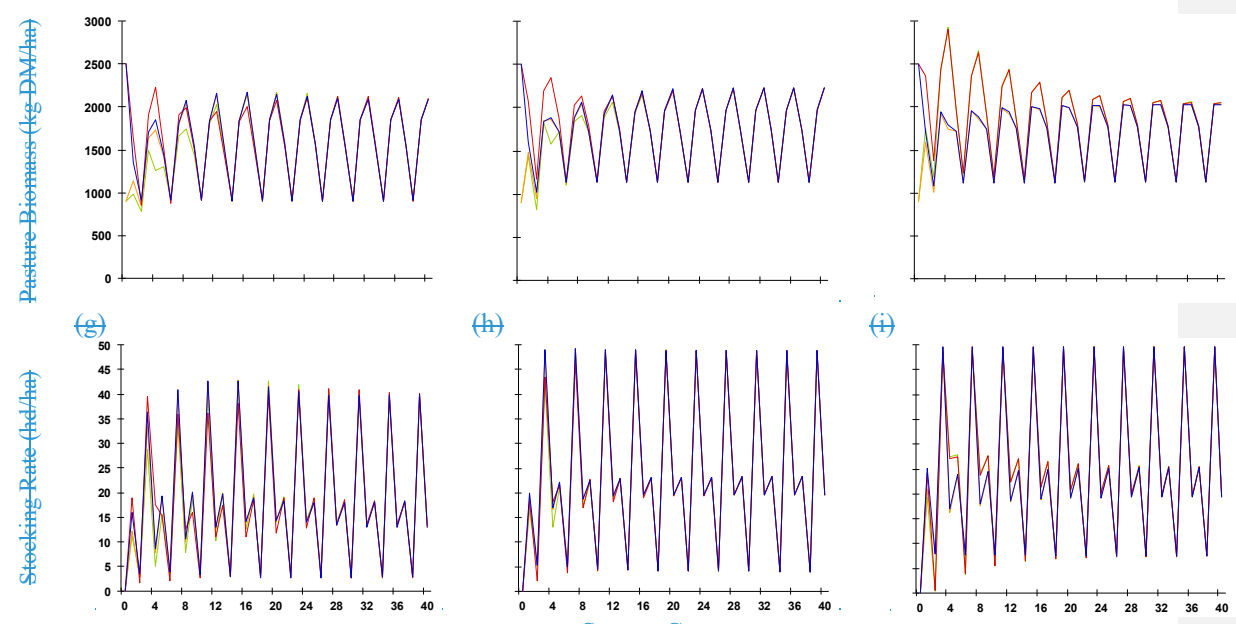

(h)

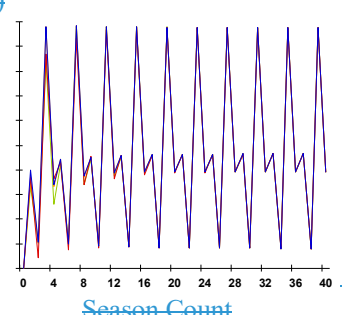

(i)

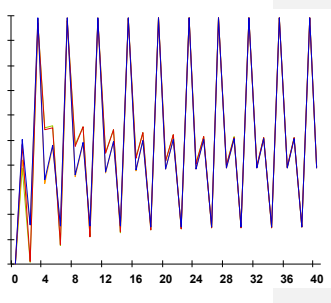

Figure 3: Long-run (sMean trajectories demonstrating policy convergence and expected optimal

target levelstationary) probabilities for pasture mass and the proportion of desirables for each

season (- - - $\underline{\text { Autumn, }}$-Winter, - - - Spring, $-\underline{\text { Summer) }}$ under optimal management in low,

moderate and high soil fertility input systems (SF), for the initial states of 0.15 desirable/ $/ 900 \mathrm{~kg}$

DM/ha (-); 0.75 desirable $/ 900 \mathrm{~kg}$ DM/ha (-); 0.15 desirable $/ 2500 \mathrm{~kg}$ DM/ha (-); and 0.75

desirable $/ 2500 \mathrm{~kg}$ DM/ha (-). Stocking rate trajectory indicates optimal sr decision for the

eorrespending pasture state with expected values shown for each seasonal distribution (circle).

907

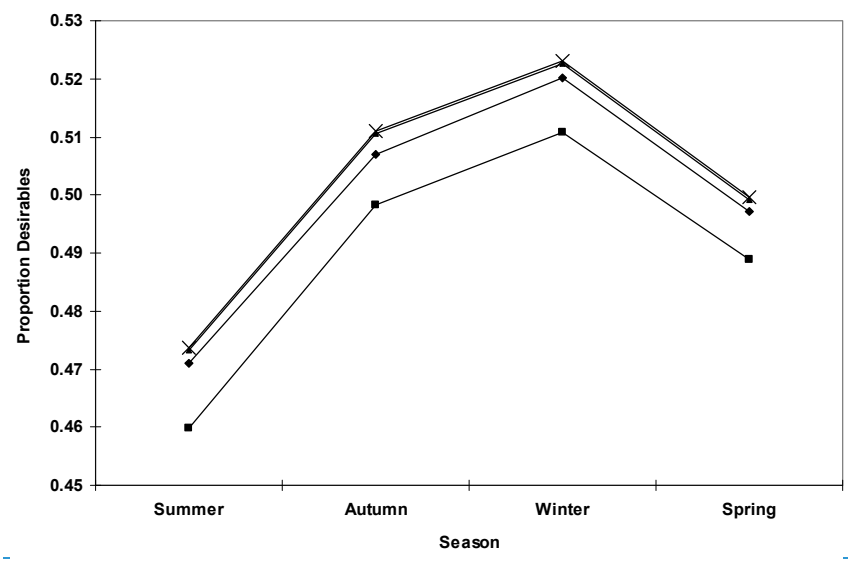




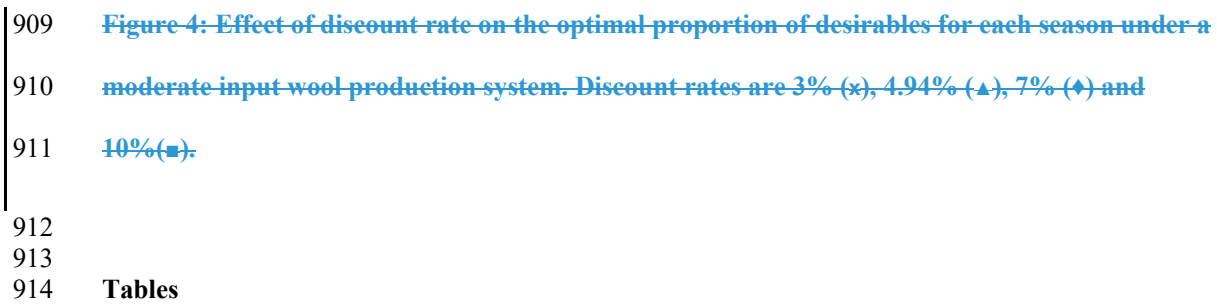

Tables

Table 1: State variables and their boundaries

Pasture Biomass for Desirable $(y d)$ and

Undesirable $(y u d)$ swards (kg DM/ha)

Proportion of Desirables $(x)$

\begin{tabular}{|c|c|c|c|c|c|}
\hline State & Minimum & Maximum & State & Minimum & Maximum \\
\hline 100 & 0 & 200 & 0.05 & 0.00 & 0.10 \\
\hline 300 & 200 & 400 & 0.15 & 0.10 & 0.20 \\
\hline 500 & 400 & 600 & 0.25 & 0.20 & 0.30 \\
\hline 700 & 600 & 800 & 0.35 & 0.30 & 0.40 \\
\hline 900 & 800 & 1000 & 0.45 & 0.40 & 0.50 \\
\hline 1250 & 1000 & 1500 & 0.55 & 0.50 & 0.60 \\
\hline 1750 & 1500 & 2000 & 0.65 & 0.60 & 0.70 \\
\hline 2500 & 2000 & 3000 & 0.75 & 0.70 & 0.80 \\
\hline 3500 & 3000 & 4000 & 0.85 & 0.80 & 0.90 \\
\hline 5000 & 4000 & $\infty$ & 0.95 & 0.90 & 1.00 \\
\hline
\end{tabular}

916

917

Table 2: Summary of state vector, $Z$.

Elements of state vector $\mathbf{z}$

\begin{tabular}{llll}
\cline { 2 - 3 } & State & $y d$ & $x$
\end{tabular}




\begin{tabular}{lccc}
\hline 1 & 100 & 100 & 0.05 \\
2 & 100 & 100 & 0.15 \\
3 & 100 & 100 & 0.25 \\
$\ldots$ & & & \\
499 & 900 & 5000 & 0.85 \\
500 & 900 & 5000 & 0.95 \\
501 & 1250 & 100 & 0.05 \\
$\ldots$. & & & \\
998 & 5000 & 5000 & 0.75 \\
999 & 5000 & 5000 & 0.85 \\
1000 & 5000 & 5000 & 0.95 \\
\hline
\end{tabular}

919

920

921

Table 3: Decision variables that make up the decision vector $\mathbf{u}_{t}^{s}$.

922

\begin{tabular}{lcc}
\hline & \multicolumn{2}{c}{ Elements of decision vector $\mathbf{u}$} \\
\cline { 2 - 3 } Decision & $s r$ & $r s$ \\
\hline 1 & 0 & 0 \\
2 & 2 & 0 \\
3 & 4 & 0 \\
4 & 8 & 0 \\
5 & 10 & 0 \\
6 & 15 & 0 \\
7 & 20 & 0 \\
8 & 30 & 0 \\
9 & 40 & 0
\end{tabular}




\begin{tabular}{lll}
10 & 50 & 0 \\
11 & 0 & 1 \\
\hline
\end{tabular}

923

924

925 Table 4: Effect of discount rate on expected values of long-run (stationary) probabilities for

926 pasture biomass and the proportion of desirables under optimal management.

\begin{tabular}{|c|c|c|c|c|}
\hline \multirow{2}{*}{ Discount Rate } & \multicolumn{4}{|c|}{ Season starting } \\
\hline & Autumn & Winter & Spring & Summer \\
\hline \multicolumn{5}{|c|}{ Pasture Biomass (kg DM/ha) } \\
\hline $3 \%$ & 2213 & 611 & 2312 & 2899 \\
\hline $5 \%$ & 2213 & 611 & 2310 & 2905 \\
\hline $7 \%$ & 2213 & 611 & 2229 & 2905 \\
\hline $10 \%$ & 2212 & 610 & 2229 & 2905 \\
\hline $20 \%$ & 2201 & 610 & 2171 & 2870 \\
\hline $50 \%$ & 2162 & 604 & 1941 & 2877 \\
\hline \multicolumn{5}{|c|}{ Proportion desirables $\left(X_{D}\right)$} \\
\hline $3 \%$ & 0.51 & 0.47 & 0.68 & 0.29 \\
\hline $5 \%$ & 0.51 & 0.47 & 0.68 & 0.28 \\
\hline $7 \%$ & 0.51 & 0.47 & 0.70 & 0.28 \\
\hline $10 \%$ & 0.51 & 0.47 & 0.70 & 0.28 \\
\hline $20 \%$ & 0.50 & 0.47 & 0.72 & 0.30 \\
\hline $50 \%$ & 0.49 & 0.46 & 0.79 & 0.30 \\
\hline
\end{tabular}

927

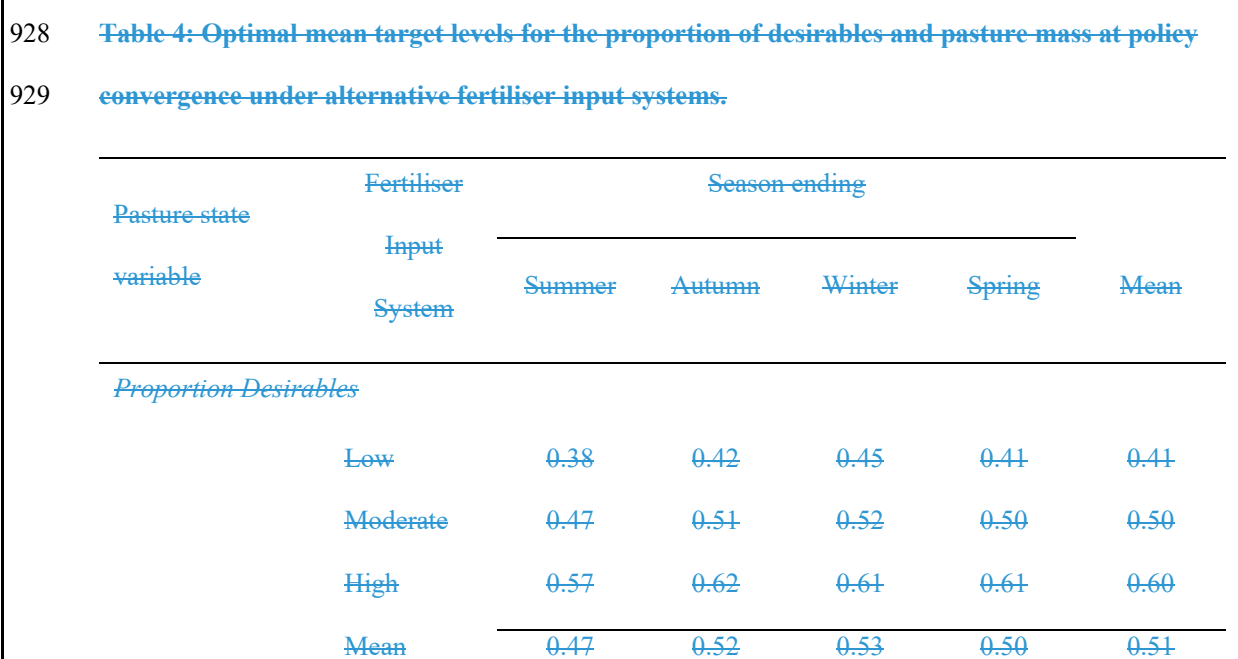




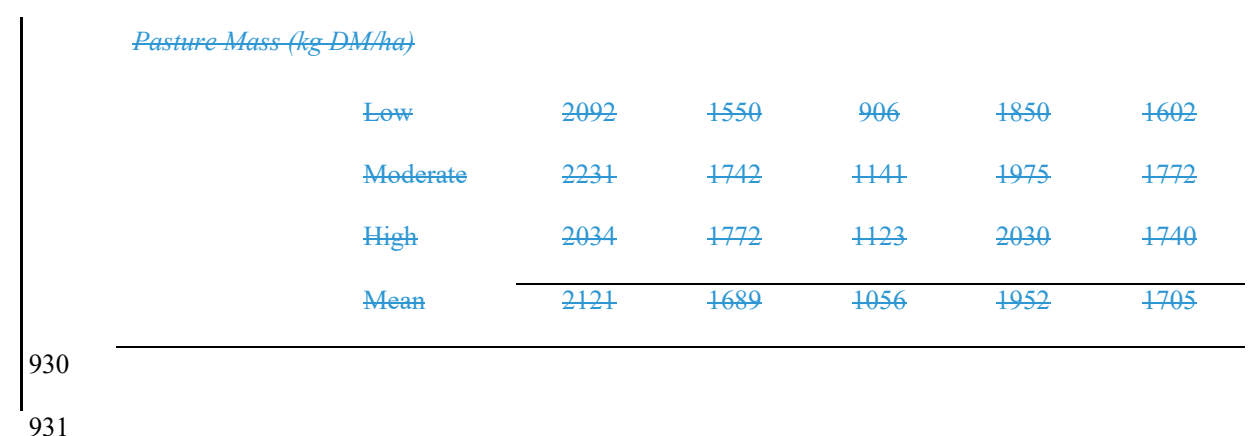

